\title{
Ralstonia solanacearum Needs Flp Pili for Virulence on Potato
}

\author{
Charles K. Wairuri, ${ }^{1}$ Jacquie E. van der Waals, ${ }^{1}$ Antoinette van Schalkwyk, ${ }^{2}$ and Jacques Theron ${ }^{1}$ \\ ${ }^{1}$ Department of Microbiology and Plant Pathology, Faculty of Natural and Agricultural Sciences, University of Pretoria, \\ Pretoria 0002, South Africa; ${ }^{2}$ Inqaba Biotechnical Industries, P.O. Box 14356, Pretoria, South Africa
}

Submitted 14 June 2011. Accepted 22 November 2011.

Type IV pili are virulence factors in various bacteria. Several subclasses of type IV pili have been described according to the characteristics of the structural prepilin subunit. Although type IVa pili have been implicated in the virulence of Ralstonia solanacearum, type IVb pili have not previously been described in this plant pathogen. Here, we report the characterization of two distinct tad loci in the $R$. solanacearum genome. The tad genes encode functions necessary for biogenesis of the Flp subfamily of type IVb pili initially described for the periodontal pathogen Aggregatibacter actinomycetemcomitans. To determine the role of the tad loci in $R$. solanacearum virulence, we mutated the $\operatorname{tad} A 2$ gene located in the megaplasmid that encodes a predicted NTPase previously reported to function as the energizer for Flp pilus biogenesis. Characterization of the tadA2 mutant revealed that it was not growth impaired in vitro or in planta, produced wild-type levels of exopolysaccharide galactosamine, and exhibited swimming and twitching motility comparable with the wild-type strain. However, the $\operatorname{tadA2}$ mutant was impaired in its ability to cause wilting of potato plants. This is the first report where type IVb pili in a phytopathogenic bacterium contribute significantly to plant pathogenesis.

Bacteria can assemble various cell surface appendages that enable them to colonize diverse biotic and abiotic surfaces. Indeed, the attachment of a pathogenic bacterium to the surface of a eukaryotic cell is an important step for successful infection, and also a prerequisite for subsequent events such as internalization and contact-dependent translocation of effector molecules by type III secretion systems (Buttner and Bonas 2002; Henderson et al. 1999). For interactions with surfaces, many bacteria make use of fimbrial or nonfimbrial adhesins (Danhorn and Faqua 2007; Gerlach and Hensel 2007). Fimbriae or pili are hair-like structures that radiate from the bacterial surface and typically consist of only one structural protein, called pilin (Pelicic 2008). Although gram-negative bacteria produce various different pili (Fronzes et al. 2008), the type IV pili (T4P) are the most abundant pili described thus far. The functions of T4P are quite diverse and they have been shown to

Nucleotide sequence data for $R$. solanacearum NB336 is available in the GenBank database under the following accession numbers: tadAl (JN998027) and tadA2 (JN968967).

Corresponding author: J. Theron; Telephone: +27 12 420-2994; Fax: +27 12 420-3266; E-mail: jacques.theron@up.ac.za

* The $e$-Xtra logo stands for "electronic extra" and indicates that four supplementary figures are published online. play an important role in adhesion of pathogenic bacteria to their host cells, biofilm formation, twitching motility, conjugative DNA transfer, and bacteriophage infection (Craig and Li 2008; Kang et al. 2002; Mattick et al. 1996; O’Toole and Kolter 1998; Wall and Kaiser 1999). Therefore, it is not surprising that pili are essential virulence factors of many bacteria.

Based on sequence similarities, T4P can be divided into type IVa (T4a) and type IVb (T4b) pili. The N-terminal signal sequence of the T4a prepilin is relatively short and consists of 5 to 6 amino acids (aa), whereas the signal sequence of T4b prepilin contains 15 to 30 aa. Mature T4a pilins have a characteristic length of 150 to 160 aa, whereas T4b pilins are either long (180 to 200 aa) or short (40 to 50 aa) (Pelicic 2008). Studies on Aggregatibacter actinomycetemcomitans, a gramnegative bacterium responsible for localized juvenile periodontitis, revealed the presence of T4b pili with specific characteristics. These include a signal sequence of variable length (10 to $26 \mathrm{aa}$ ), a relatively short mature pilin (smaller than $90 \mathrm{aa}$ ), and a shared "Flp" motif of 20 hydrophobic residues at the $\mathrm{N}$ terminus of the mature pilin, with adjacent glutamate and tyrosine residues in its center (Kachlany et al. 2001; Planet et al. 2003). Due to its unique features, it has been described as the Flp subfamily of T4b pili (Kachlany et al. 2001). In A. actinomycetemcomitans, the Flp pilin requires for its assembly a subset of components, called Tad and Rcp, which includes the RcpA secretin (Clock et al. 2008), the TadD pilotin or docking protein (Clock et al. 2008), the TadA trafficking NTPase (Bhattacharjee et al. 2001), the PilC-like proteins TadB and TadC (Wang and Chen 2005), the TadE and TadF pseudopilins (Kachlany et al. 2000), and the TadV prepilin peptidase (Perez et al. 2006; Tomich et al. 2006). The genes of other Tad system components (RcpB, RcpC, TadG, and TadZ) do not show extensive homologies to any genes and have not been assigned predicted functions.

Some tad loci similar to that described in A. actinomycetemcomitans have been identified in a variety of bacterial and archaeal species, usually as a single copy but in up to four copies in some species (Kachlany et al. 2000; Planet et al. 2003; Tomich et al. 2007). Comparative phylogenetic analysis suggests that many bacterial species have acquired tad genes from foreign sources and, because of its apparent propensity for horizontal gene transfer, the tad locus has also been named a widespread colonization island (Planet et al. 2003). The tad locus has been implicated in the pathogenesis of several bacteria, including A. actinomycetemcomitans (Schreiner et al. 2003), Haemophilus ducreyi (Nika et al. 2002; Spinola et al. 2003), Yersinia ruckeri (Fernandez et al. 2004), and Pasteurella multocida (Fuller et al. 2000). In contrast to these human- and animal-pathogenic bacteria, the functional significance of the tad locus in phytopathogenic bacteria has not yet been reported. 
Ralstonia solanacearum is a soilborne gram-negative bacterium that causes bacterial wilt disease in more than 200 plant species, representing over 50 botanical families (Hayward 1991; Swanson et al. 2005). Among these, solanaceous plants, including economically significant hosts of global importance such as potato, tomato, peanut, and eggplant, are the most affected species (Janse et al. 2004). Due to its wide geographic distribution and unusually broad host range, the pathogen is responsible for severe crop losses worldwide. $R$. solanacearum normally invades plant roots through wounds or where secondary roots emerge, penetrates the xylem, and then systematically colonizes the vascular system. Extensive colonization disrupts vascular function and the plants rapidly wilt and die (Schell 2000; Vasse et al. 2005). $R$. solanacearum possesses various virulence factors that act quantitatively to cause disease. In addition to extracellular polysaccharide I (Denny and Baek 1991; McGarvey et al. 1999), cell-wall-degrading enzymes (Gonzalez and Allen 2003; Liu et al. 2005), and type III-secreted effectors (Cunnac et al. 2004), flagellar-driven swimming and pilus-driven twitching motility are also necessary for virulence (Liu et al. 2001; TansKersten et al. 2001). All of these virulence factors are controlled by a complex regulatory signal transduction pathway (Hikichi et al. 2007; Schell 2000) that responds to both environmental signals and quorum sensing (Brito et al. 1999). Although much is understood about these virulence factors and their regulation, less is known about how $R$. solanacearum effectively adheres, colonizes, and spreads in the host.

To enrich our knowledge of the gene machinery required by $R$. solanacearum to cause disease in host plants, we mined the complete genome sequence of $R$. solanacearum GMI1000 (Salanoubat et al. 2002) and identified a number of genes ho- mologous to the flp-rcp-tad genes previously characterized in A. actinomycetemcomitans (Kachlany et al. 2000). We made use of a targeted mutagenesis strategy, coupled with genetic complementation analysis, to evaluate the role of Flp pili in $R$. solanacearum virulence and other properties. We report that a mutant strain, derived from mutagenesis of the $R$. solanacearum tadA2 gene in the megaplasmid tad locus, displayed significantly reduced virulence on potato plants.

\section{RESULTS}

Characterization of $\boldsymbol{R}$. solanacearum tad gene clusters.

Mining of the $R$. solanacearum GMI1000 genome identified two distinct tad-like gene clusters present in the megaplasmid and chromosome, respectively, which each harbor genes with similarity to the flp-rcp-tad genes previously identified in $A$. actinomycetemcomitans (Kachlany et al. 2000). Indeed, most of the genes of the tad locus from A. actinomycetemcomitans can be identified in a similar genetic organization in the respective tad loci of $R$. solanacearum (Fig. 1A). The transcriptional organization of the $R$. solanacearum tad loci, however, is not yet known.

The names and characteristics attributed to the RSp1079-toRSp1092 open reading frames (ORF) that compose the putative tad locus in the $R$. solanacearum GMI1000 megaplasmid are provided in Table 1. The RSp1092 ORF was identified as an flp-like gene (Kachlany et al. 2001; Perez et al. 2006). The putative Flp precursor displays features characteristic of the Flp subfamily of T4b pili (Fig. 1B). As indicated earlier, these include a relatively short mature pilin (44 aa) and a Flp motif at the $\mathrm{N}$ terminus of the mature pilin. In addition, it contains a

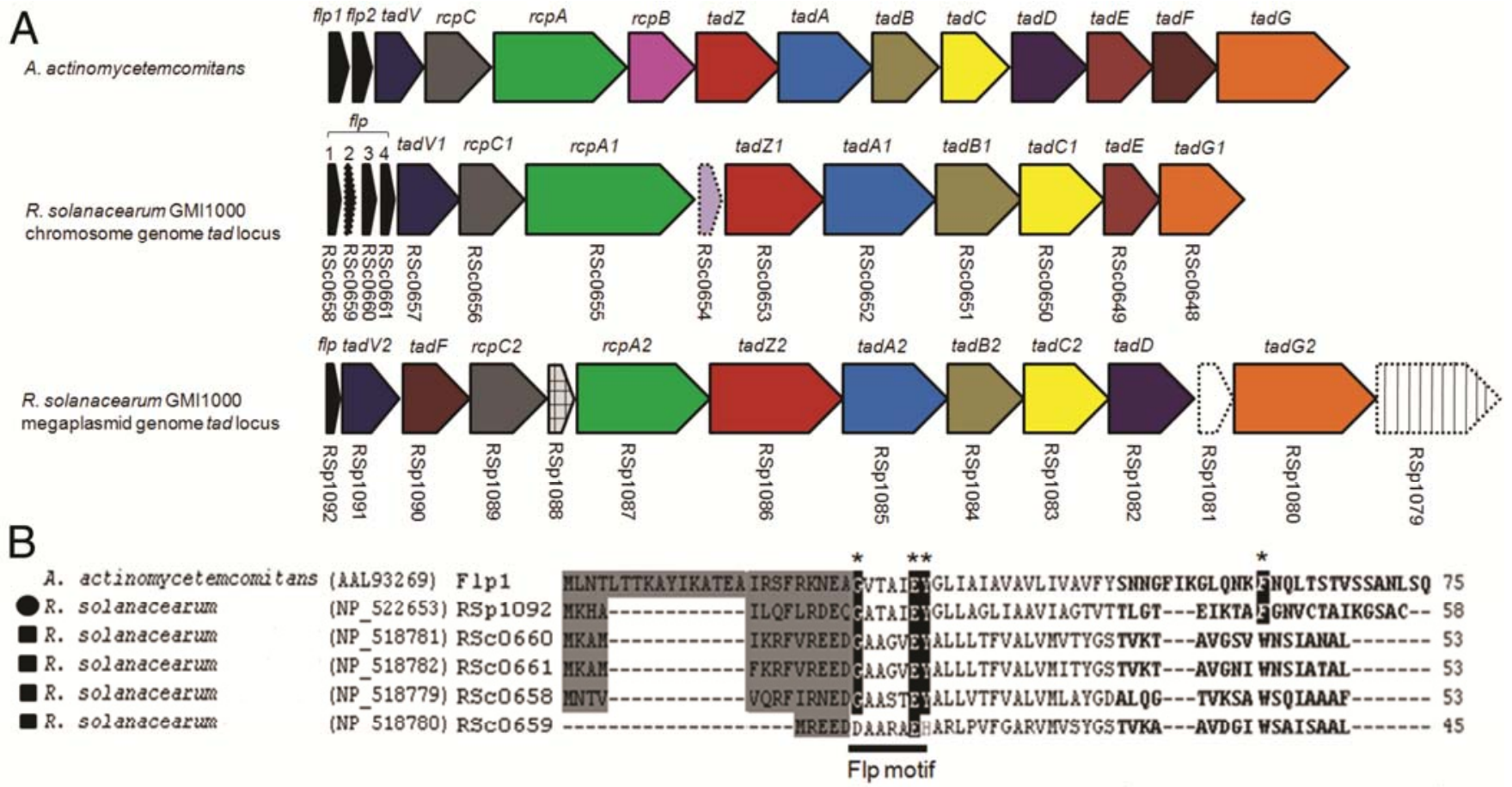

Leaderpeptide

Hydrophobic region

Hydrophilic variable carboxy terminus

Fig. 1. The tad gene clusters of Ralstonia solanacearum. A, Genetic organization of megaplasmid and chromosomal tad gene clusters in R. solanacearum GMI1000 compared with the homologous gene cluster of Aggregatibacter actinomycetemcomitans (Kram et al. 2008). Open reading frames (ORF) with similar predicted protein products are indicated in the same color. The transcriptional orientation and approximate size of the different ORF are indicated by the direction and the length of the arrows. ORF that are unique to the $R$. solanacearum megaplasmid and chromosomal tad loci are indicated by dashed outlines. B, Alignment of the putative Flp prepilin proteins of $R$. solanacearum and Flp- 1 of A. actinomycetemcomitans. The Flp motif is underlined and the conserved glycine $(\mathrm{G})$, glutamate $(\mathrm{E})$, and tyrosine $(\mathrm{Y})$ residues in the Flp motif, as well as the phenylalanine (F) residue frequently found within the C-terminal region of Flp pili, are indicated by asterisks. The putative Flp prepilin proteins encoded by the megaplasmid and chromosomal tad loci of $R$. solanacearum are indicated by a circle and squares, respectively. For all sequences included in the analysis, the GenBank accession numbers are indicated in brackets. 
phenylalanine (Phe) residue toward its $\mathrm{C}$ terminus that is conserved in most predicted Flp proteins (Kachlany et al. 2001). The megaplasmid tad locus, however, lacks homologues of the $f l p-2, r c p B$, and $t a d E$ genes, which are found in the A. actinomycetemcomitans flp-rcp-tad gene cluster. Notably, $r c p B$ has been identified thus far only in the tad loci of members of the family Pasteurellaceae (Perez et al. 2006) whereas flp-2, in contrast to $f l p-1$, is not required for the production of Flp pili or for adherence of A. actinomycetemcomitans (Perez et al. 2006). Moreover, the tad locus of several bacteria encodes only a single pseudopilin protein (TadE or TadF) (Tomich et al. 2007) which, in the case of Pseudomonas aeruginosa, has been reported to be dispensable for Flp biogenesis (Bernard et al. 2009). No obvious homology could be found between the putative proteins encoded by RSp1079, RSp1081, and RSp1088 and the Flp-Tad-Rcp system of A. actinomycetemcomitans. However, RSp1081 encodes a putative homologue of PA4298 which, thus far, has been reported only in the tad locus of $P$. aeruginosa; however, its function is not yet known (de Bentzmann et al. 2006).

The $R$. solanacearum GMI1000 chromosomal tad locus also contains 14 ORF (RSc0648 through RSc0661) but it lacks homologues to three ORF in the megaplasmid tad locus (i.e., RSp1079, RSp1081, and RSp1088) and encodes four putative Flp prepilin proteins. The Flp putative proteins all lack a Phe residue at the $\mathrm{C}$ terminus, while the putative protein encoded by RSc0659 lacks the Flp motif (Fig. 1B). In addition to lacking homologues of $r c p B$ and $t a d F$, no obvious homologue of the $A$. actinomycetemcomitans tadD gene could be identified in the chromosomal tad locus. The TadD protein of A. actinomycetemcomitans is localized to the bacterial outer membrane and has been reported to be critical for the assembly, transport, and functioning of the secretion complex (Clock et al. 2008; Tomich et al. 2007). Moreover, during in vivo assays to identify virulence genes, $t a d D$ was identified as essential for virulence in Pasteurella multocida and Yersinia ruckeri (Fernandez et al. 2004; Fuller et al. 2000). Finally, no obvious homology could be found between the putative protein encoded by the RSc0654 ORF and the Flp-Tad-Rcp system of A. actinomycetemcomitans. The ORF composing the chromosomal tad locus have been renamed in accordance with the Flp-Rcp-Tad nomenclature (Table 1).

Considering the genetic variability among $R$. solanacearum strains, it was of interest to determine whether the tad loci also occur in strains other than the GMI1000 strain. Analysis of the genome sequences of five $R$. solanacearum strains (CMR15, PSI07, CFBP2957, IPO1609, and Po82) indicated the presence of similar tad loci in the megaplasmid and chromosome of these strains (Supplementary Fig. S1). Compared with the $R$. solanacearum GMI1000 megaplasmid tad locus, all five strains analyzed lacked a homologue of RSp1088, whereas strain Po82 also lacked a homologue of RSp1081. Comparison of the chromosomal tad loci indicated the presence of homologues to each of the ORF in the $R$. solanacearum GMI1000 chromosomal tad locus but the strains differed with regard to the number of putative flp alleles and ranged between two and five clustered $f l p$ alleles. These results suggest that the presence of tad loci may be common among $R$. solanacearum strains.

\section{Construction of $R$. solanacearum NB336-1085 mutant.}

Although the genome sequence of $R$. solanacearum NB336 is not known, it is likely that this strain, like other $R$. solanacearum strains, also harbors two tad loci. Polymerase chain reaction (PCR) amplification and sequencing revealed that the coding regions of the tadAl (GenBank accession number JN998027) and tadA2 (GenBank accession number JN968967) genes of NB336 were similar to those of $R$. solanacearum GMI1000 (95 and $99 \%$ amino acid sequence similarity, respectively) (data not shown). To generate an $R$. solanacearum mutant strain that would be useful in subsequent studies, we introduced a targeted mutation into the putative $\operatorname{tad} A 2$ gene present in the megaplasmid tad locus of $R$. solanacearum NB336. This was based on the following considerations: i) most of the virulence genes of $R$. solanacearum are reported to be located in the megaplasmid (Genin and Boucher 2004; Salanoubat et al. 2002); ii) the megaplasmid tad locus contains a TadD homologue, which has been implicated as being required for proper secretin assembly and function (Clock et al. 2008); iii) the $\operatorname{tadA}$ gene is highly conserved in the tad loci of different bacteria (Planet et al. 2001; Tomich et al. 2007); iv) the tadA gene encodes an NTPase essential for energizing the assembly or secretion of Flp pili in A. actinomycetemcomitans (Bhattarcharjee et al. 2001); v) inactivation of the TadA proteins of A. actinomycetemcomitans and $H$. ducreyi results in bacterial strains attenuated for virulence (Schreiner et al. 2003; Spinola et al. 2003); and vi) tadA mutants of human-pathogenic bacteria lack Flp pili on the surface of the cells (Bhattarcharjee et al. 2001; de Bentzmann et al. 2006; Nika et al. 2002).

Table 1. Characteristics of the Ralstonia solanacearum tad loci ${ }^{\mathrm{a}}$

\begin{tabular}{|c|c|c|c|c|c|c|}
\hline \multicolumn{3}{|c|}{ Chromosome tad locus } & \multicolumn{4}{|c|}{ Megaplasmid tad locus } \\
\hline Gene name & RSc number & Protein size (aa) & Gene name & RSp number & Protein size (aa) & Predicted function \\
\hline$f l p-1$ & 0661 & 53 & $f l p$ & 1092 & 58 & Pilin \\
\hline$f l p-2$ & 0660 & 53 & $\ldots$ & $\ldots$ & $\ldots$ & Pilin \\
\hline$f l p-3$ & 0659 & 45 & $\ldots$ & $\ldots$ & $\ldots$ & Pilin \\
\hline flp-4 & 0658 & 53 & $\ldots$ & $\ldots$ & $\ldots$ & Pilin \\
\hline tadV1 & 0657 & 172 & tadV2 2 & 1091 & 168 & Prepilin peptidase \\
\hline$\ldots$ & & & $\operatorname{tad} F$ & 1090 & 163 & Pseudopilin \\
\hline $\operatorname{rcpCl}$ & 0656 & 288 & rcpC2 & 1089 & 208 & ... \\
\hline$\ldots$ & $\ldots$ & $\ldots$ & $\ldots$ & 1088 & 105 & $\ldots$ \\
\hline rсpAl & 0655 & 634 & rсрA2 & 1087 & 454 & Secretin \\
\hline$\ldots$ & 0654 & 102 & $\ldots$ & $\ldots$ & $\ldots$ & $\ldots$ \\
\hline $\operatorname{tadZ1}$ & 0653 & 397 & $\operatorname{tadZ2}$ & 1086 & 439 & \\
\hline tadAl & 0652 & 453 & $\operatorname{tad} A 2$ & 1085 & 450 & ATPase \\
\hline $\operatorname{tadB1}$ & 0651 & 325 & $\operatorname{tadB2}$ & 1084 & 308 & PilC-like \\
\hline $\operatorname{tad} C 1$ & 0650 & 315 & $\operatorname{tad} C 2$ & 1083 & 326 & PilC-like \\
\hline$\ldots$ & $\ldots$ & $\ldots$ & $\operatorname{tad} D$ & 1082 & 305 & $\begin{array}{l}\text { Pilotin } \\
\text { Pan }\end{array}$ \\
\hline$\ldots$ & $\ldots$ & $\ldots$ & $\ldots$ & 1081 & 109 & \\
\hline $\operatorname{tad} E$ & 0649 & 144 & $\ldots$ & $\ldots$ & $\ldots$ & Pseudopilin \\
\hline $\operatorname{tad} G 1$ & 0648 & 347 & tadG2 & 1080 & 540 & ... \\
\hline$\ldots$ & $\ldots$ & $\ldots$ & $\ldots$ & 1079 & 467 & $\cdots$ \\
\hline
\end{tabular}

\footnotetext{
${ }^{\text {a }} \mathrm{RSp}$ and RSc numbers correspond to the genome annotation of $R$. solanacearum GMI1000; aa $=$ amino acids.
} 
We generated a mutant $\operatorname{tad} A 2$ allele by excising an internal fragment of the subcloned tadA2 ORF, thus deleting the conserved Asp and His boxes and the Walker B motif that are all essential for NTPase functioning (Possot and Pugsly 1994; Whitchurch et al. 1991) and replacing it with a gentamycin resistance cassette. The mutagenesis construct was then introduced into the megaplasmid of the wild-type strain NB336 by allelic replacement to generate the mutant strain NB336-1085. The wild-type and mutant $R$. solanacearum strains were subsequently examined for the presence of potential Flp pili. Transmission electron microscopy (TEM) revealed differences between the wild-type and mutant $R$. solanacearum cells with regard to the cell-surface appendages present (Fig. 2). Negative staining of the wild-type NB336 strain revealed the presence of flagella, pili, and darkly stained, thick-bundled pili structures. In contrast, the latter exostructures were not observed in the NB336-1085 mutant strain. The bundled pili, referred to as Flp pili, could be differentiated readily from other pili. They were less abundant, stained darker, and comprised bundles of long, thin pili. Complementation of the mutant strain with a copy of the wild-type tadA2 gene in trans restored the wild-type phenotype, albeit that the long, bundled fibrils were thinner and appeared less rigid.

\section{Phenotypic characterization of $R$. solanacearum $\mathrm{NB336}-1085$.}

To determine whether mutagenesis had unintended side effects, we compared the $R$. solanacearum strains for traits known to affect virulence such as elicitation of a hypersensitive reaction (HR), exopolysaccharide (EPS) galactosamine production, and motility. The results of these phenotypic assays are provided in Supplementary Figures S2 to S4. The NB336-1085 mutant strain had mucoid colony morphology on TZC agar (Kelman 1954) and grew as well as the wild-type NB336 strain in CPG broth (Hendrick and Sequeira 1984) (data not shown) and in planta (Fig. 3). The NB336-1085 mutant elicited a normal wild-type HR defense response when infiltrated into non-host tobacco leaves, indicating that Hrp pili and the rest of the type III secretion system was not affected by the introduction of the mutant allele. Galactosamine is a major constituent of the acidic EPS I polymer (Araud-Razou et al. 1998; Denny et al. 1988) and considered to be a reliable indicator of the total EPS produced (Brumbley and Denny 1990). Quantification of the EPS galactosamine produced by the $R$. solanacearum strains indicated that that they produced similar amounts of EPS galactosamine and, therefore, the membrane-localized functions for EPS I biosynthesis were not affected in the mutant strain.

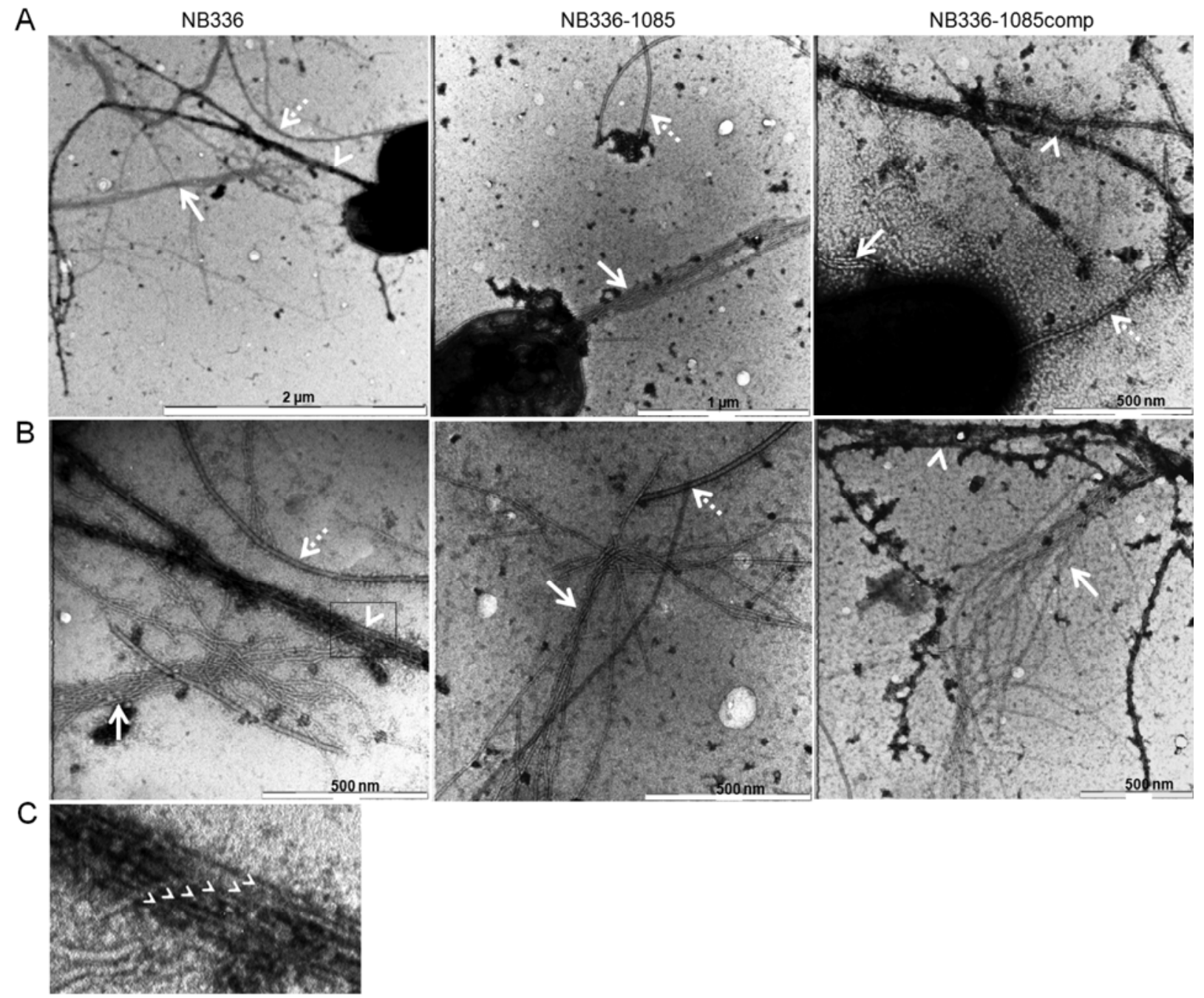

Fig. 2. Transmission electron microscopy of Ralstonia solanacearum strains, following growth for $48 \mathrm{~h}$ in broth supplemented with glutamate (20 mM). Micrographs are shown of A, negatively stained wild-type NB366, mutant NB336-1085, and complemented mutant NB336-1085comp bacterial cells and B, loose fimbriae detected in the growth medium of the respective $R$. solanacearum strains. Flagella (dashed arrows) and abundant weakly contrasted pili (solid arrows) could be observed in negative preparations of all these $R$. solanacearum strains, whereas the mutant NB336-1085 strain lacked the well-contrasted bundled pili that we referred to as Flp pili (arrowheads). C, Enlarged view of a Flp fibril produced by the wild-type NB336 strain (boxed area in B), which is composed of a parallel array of six thin, tightly packed individual pili. 
On motility agar, colonies of the $R$. solanacearum strains were surrounded by an even, white halo, indicative of flagellum-driven motility, and the motility halo of each strain was similar in size. To assess twitching motility, the bacterial colonies on CPG agar were compared under a light microscope. Individual rafts of cells with jagged edges were observed, indicating that they were the result of cells migrating over the agar surface rather than being due to multiplication away from the center of the colony. Thus, the NB336-1085 mutant strain displayed swimming and twitching motility comparable with that of the wild-type NB336 strain, indicating normal production of flagella and T4a pili.

\section{R. solanacearum NB336-1085 displays reduced virulence.}

To evaluate the virulence of the NB336-1085 mutant strain, we performed two types of virulence assay on a susceptible potato host. In the naturalistic soil soak assay, which requires bacteria to locate and invade host roots from the soil (TansKersten et al. 2001), wild-type NB336 caused a disease index of 3.94 at 16 days after inoculation and 4 at 30 days after inoculation. In contrast, the NB336-1085 mutant strain did not cause wilting over the 30-day period. Notably, the complemented mutant strain NB336-1085comp restored the virulence phenotype. Although the NB336-1085comp strain caused a disease index of 4 at 29 days, it was significantly $(P=0.05)$ slower than the wild-type strain in causing wilting according to Tukey's honestly significant difference (HSD) test performed on each of days 8 to 23 (Fig. 4A). In a cut-petiole assay, which bypasses the normal infection route and introduces bacteria directly into the vascular system (Liu et al. 2001), the wildtype NB336 strain wilted all potato plants by day 12 after inoculation. The NB336-1085comp strain wilted all potato plants by day 16 and was statistically indistinguishable from the wild-type strain in this assay. However, potato plants inoculated with the NB336-1085 mutant strain did not wilt (Fig. 4B) and developed only restricted leaf yellowing and localized necrosis (Fig. 4C). In both of these assays, the complemented mutant strain induced wilting at a lower rate than the wild-type NB336 strain, possibly because of differences in the tadA2 expression level due to copy number or promoter effects. Nevertheless, these results suggested that the megaplasmid tad locus of $R$. solanacearum, or functions that require the tadA2encoded protein, is important for virulence on potato plants.

\section{Biofilm formation is affected on an abiotic surface.}

Many plant-associated bacteria, including $R$. solanacearum, form biofilms in contact with biotic or abiotic environments (Danhorn and Fuqua 2007; Morris and Monier 2003). Because Flp pili have been shown to mediate biofilm development (de Bentzmann et al. 2006; Kachlany et al. 2000; Nika et al. 2002), we sought to characterize biofilm formation of the wild-type and mutant strains by making use of quantitative PVC microtiter plate assays. After the $R$. solanacearum strains were incubated for $48 \mathrm{~h}$ at $30^{\circ} \mathrm{C}$, biofilm bands were observed at the air-liquid interface. Interestingly, the NB336-1085 mutant strain formed significantly more biofilm than the wildtype NB336 strain. However, strain NB336-1085comp, in which the mutation was complemented in trans, produced a similar amount of biofilm compared with the wild-type NB336 strain (Fig. 5). These results indicated that the ability of the NB336-1085 mutant strain to form biofilms was significantly enhanced under the tested conditions.

\section{DISCUSSION}

Bioinformatic analyses revealed the presence of two distinct 14-gene tad loci located in the chromosome and megaplasmid of $R$. solanacearum GMI1000, and similar tad loci were also identified in the sequenced genomes of other $R$. solanacearum strains. The tad genes encode homologues of components reported previously in A. actinomycetemcomitans (Kachlany et al. 2000) to be involved in the biogenesis of Flp pili. This subfamily of $\mathrm{T} 4 \mathrm{~b}$ pili has since been reported to contribute to the virulence of several human- and animal-pathogenic bacteria species (Fuller et al. 2000; Schreiner et al. 2003; Spinola et al. 2003). Why $R$. solanacearum has two distinct tad loci is not clear but phylogenetic analyses have indicated that the tad locus has experienced a complex history of duplication, loss, gene shuffling (recombination), and horizontal gene transfer between distant bacterial relatives (Planet et al. 2001, 2003). Nevertheless, the widespread existence of the tad locus (Planet et al. 2003; Tomich et al. 2007) suggests that there exists a

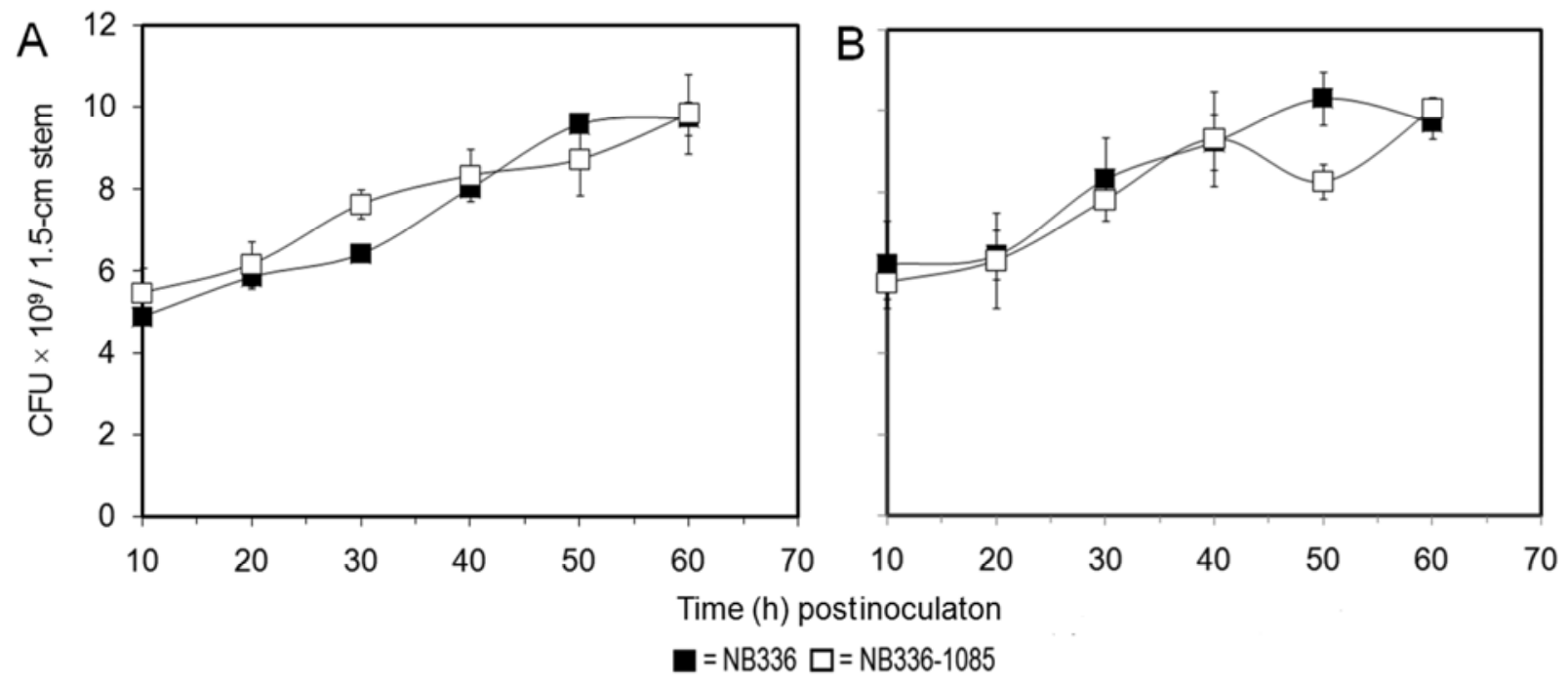

Fig. 3. In planta growth of the Ralstonia solanacearum wild-type NB336 and mutant NB336-1085 strains. Stems of potato plants were inoculated with $5 \times$ $10^{5}$ bacteria and the plants were incubated in a greenhouse at 28 to $30^{\circ} \mathrm{C}$. At 10 -h time intervals postinoculation, 1.5 -cm stem segments $\mathbf{A}$, above and $\mathbf{B}$, below the point of inoculation were excised, surface sterilized, and homogenized, and the number of bacterial CFU recovered was determined by dilution plating onto TZC agar medium. The results are the mean of three independent experiments and the error bars represent the standard error of the mean. The growth of the respective strains were not significantly different $(P=0.05)$ at any of the time points according to Tukey's honestly significant difference test. 
strong selective pressure for the maintenance of this gene cluster across a diverse spectrum of bacterial species. Therefore, it is reasonable to assume that the protein products encoded by this gene cluster may be important for some aspect of the life cycle of the organisms that contain these genes. In this study, we have investigated the relevance of the megaplasmid tad gene cluster in $R$. solanacearum virulence on potato plants.

Results obtained in this study indicated that mutagenesis of the tadA2 gene located in the megaplasmid tad locus yielded phenotypes that could be rescued if a wild-type copy of the tadA2 gene was provided in trans to the NB336-1085 mutant strain. It is tempting to speculate that the absence of a $\operatorname{tadD}$ homologue in the chromosomal tad locus may prevent the proper assembly of the RcpA secretin of the Flp biogenesis apparatus, thus prohibiting the proper assembly or secretion of the Flp pilus. Moreover, in silico analyses revealed that the chromosomal tad locus has the genetic information to produce three similar Flp-like proteins (RSc0659 lacks an Flp motif). Whether one or more of the putative flp genes in this tad locus may represent pseudogenes that have become dispensable for
Flp pilin biogenesis, as in the case of flp-2 of A. actinomycetemcomitans (Perez et al. 2006), or might still have a function is yet to be determined. Alternatively, it may also be possible that the chromosomal tad gene cluster is not expressed under the conditions used in this study. In contrast, although the tad locus in the $R$. solanacearum megaplasmid lacks homologues of genes present within the tad gene cluster of A. actinomycetemcomitans (e.g., a second flp gene, second pseudopilin gene, and $r c p B$ gene), it may still be able to function as an Flp pilus biogenesis and secretion system. This is based on the observation that Pseudomonas aeruginosa, which also lacks homologues of these tad genes, is capable of assembling functional Flp pili in their absence (de Bentzmann et al. 2006).

Literature regarding pili in $R$. solanacearum suggests that this bacterium is capable of producing various types of pili. Characterization of $R$. solanacearum strains GMI1000 (van Gijsegem et al. 2000) and AWI (Kang et al. 2002) indicated that they each produce two distinct types of pili (i.e., the HrpY pilus encoded by the $h r p Y$ gene and the T4a pilus encoded by the pilA gene). In addition to these reports, Stemmer
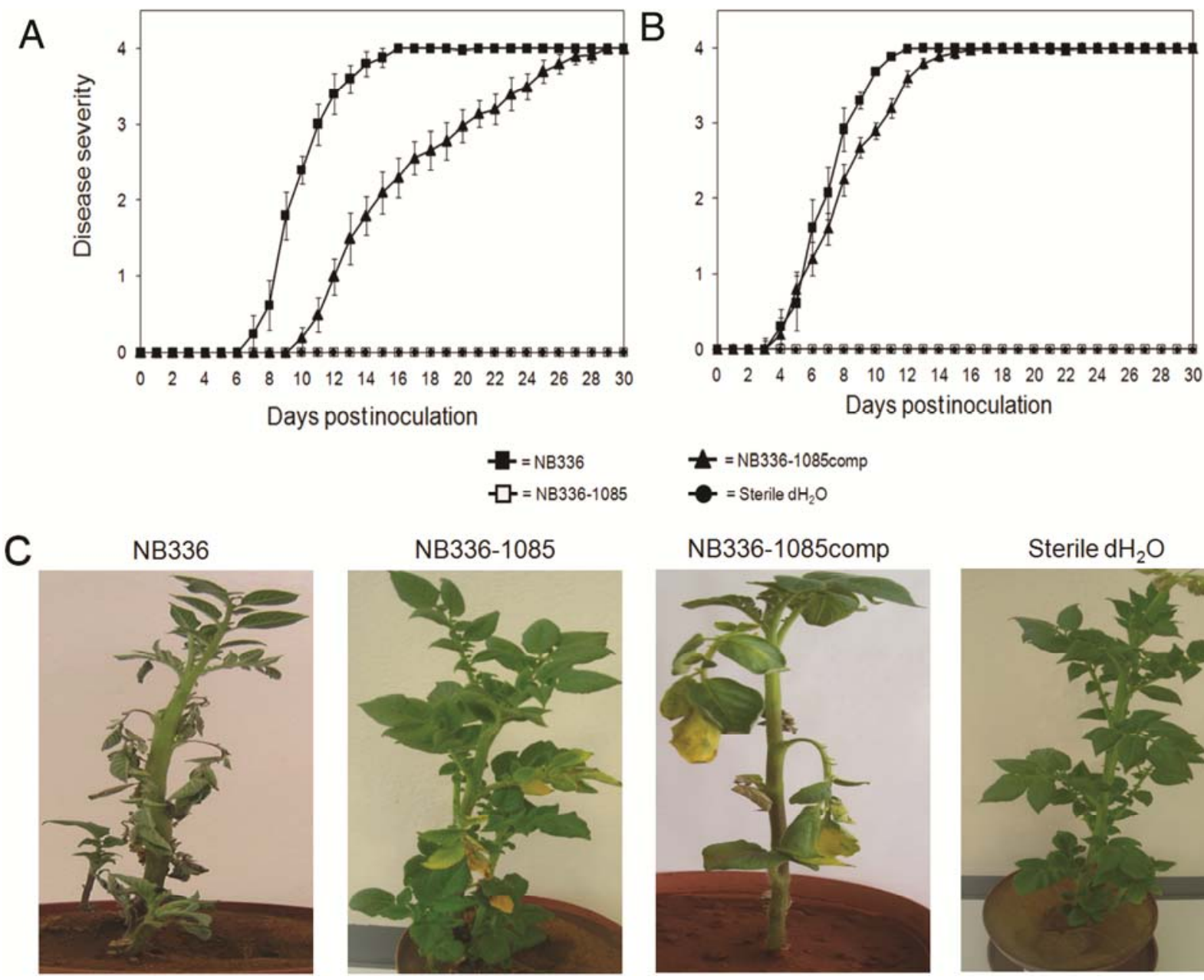

C
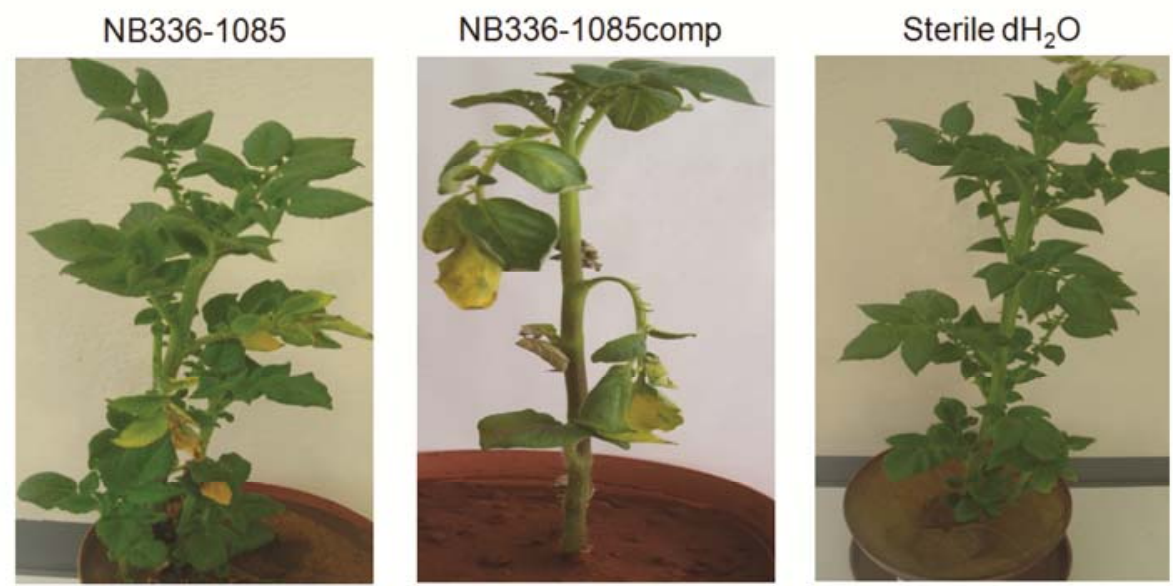

Fig. 4. Disease progress of the Ralstonia solanacearum strains on potato plants by different inoculation methods. Thirty-day-old potato plants were inoculated either by $\mathbf{A}$, soaking the soil to a final bacterial population of approximately $1 \times 10^{8} \mathrm{CFU} / \mathrm{g}$ of soil or $\mathbf{B}$, applying $5 \times 10^{5}$ bacteria directly to the cut surface of a leaf petiole. In these assays, plants inoculated with sterile distilled water $\left(\mathrm{dH}_{2} \mathrm{O}\right)$ were included as a negative control. Plants were rated daily on a disease index scale from 0 to 4 . Each point represents the mean disease index of three individual experiments, each containing five plants per treatment. A, Virulence of the wild-type and the complemented mutant strains was significantly different from that of the mutant NB336-1085 strain, and the virulence of the complemented strain was significantly different from the wild-type strain according to Tukey's honestly significant difference test performed at each of days 8 to $23(P=0.05)$. B, Virulence of the wild-type and complemented mutant strains was not significantly different, although both differed significantly from that of the mutant NB336-1085 strain $(P=0.05)$. C, Disease symptoms of potato plants inoculated with the $R$. solanacearum strains by cut-petiole inoculation. Pictures were taken at 10 days postinoculation of potato plants used in the virulence assay presented in B. Potato plants inoculated with the wild-type NB336 strain and the complemented mutant strain NB336-1085comp showed green and yellow wilting, respectively, whereas potato plants inoculated with the mutant NB336-1085 strain exhibited restricted leaf yellowing but could be maintained until maturity without dying. Potato plants inoculated with sterile $\mathrm{dH}_{2} \mathrm{O}$ was used as a negative control. 
and Sequeira (1987) reported purified pilin protein from $R$. solanacearum K60 of which neither the molecular mass nor the amino acid compositions matched either HrpY or T4a pilins. This result indicates the presence of at least a third distinct type of pilus in $R$. solanacearum. It has been reported that HrpY pili are not involved in adherence (Aldon et al. 2000; van Gijsegem et al. 2000) and the absence of T4a pili was reported to have no quantitative effect on adherence to host or non-host cells (Kang et al. 2002), thus suggesting the presence of an as-yet-uncharacterized attachment factor. The results of this study indicate that the $R$. solanacearum megaplasmid tad gene cluster may encode a functional system that is responsible for the assembly of Flp pili. In contrast to the wild-type NB336 strain, no Flp-like pili could be seen in TEM preparations of the mutant strain NB336-1085, in which the tadA2 gene encoding the traffic NTPase was mutated. This is in agreement with previous reports indicating that mutants deficient in TadA are devoid of Flp pili (Bhattarcharjee et al. 2001; de Bentzmann et al. 2006; Kachlany et al. 2000; Nika et al. 2002).

Characterization of the nonpolar mutant strain NB336-1085 indicated that it had a mucoid colony morphology on solid medium, grew as well as the wild-type strain in medium and in planta, elicited a normal hypersensitivity response, was not affected in its ability to produce EPS galactosamine, and showed wild-type swimming and twitching motility. The wildtype and mutant strains, however, differed from each other with regard to virulence and biofilm formation. Therefore, this suggests that a functional $\operatorname{tad} A 2$ gene and, thus, Flp pili, play an important role during disease development.

$R$. solanacearum enters plants through the roots, penetrates the xylem, systemically colonizes the stem, and causes wilt symptoms (Vasse et al. 1995, 2005). During the soil-inhabiting phase, swimming motility mediated by means of flagella (TansKersten et al. 2001) as well as chemotaxis (Yao and Allen 2006) and aerotaxis (Yao and Allen 2007) may be crucial to respond to and move toward gradients of root exudates to start the infection process. Once inside the confined environment of the xylem vessels, twitching motility mediated by T4a pili may be important to the bacterium to spread and colonize other parts of the infected plant and overcome nutrient limitations (Kang et al. 2002). In this study, we have used two different inocula-

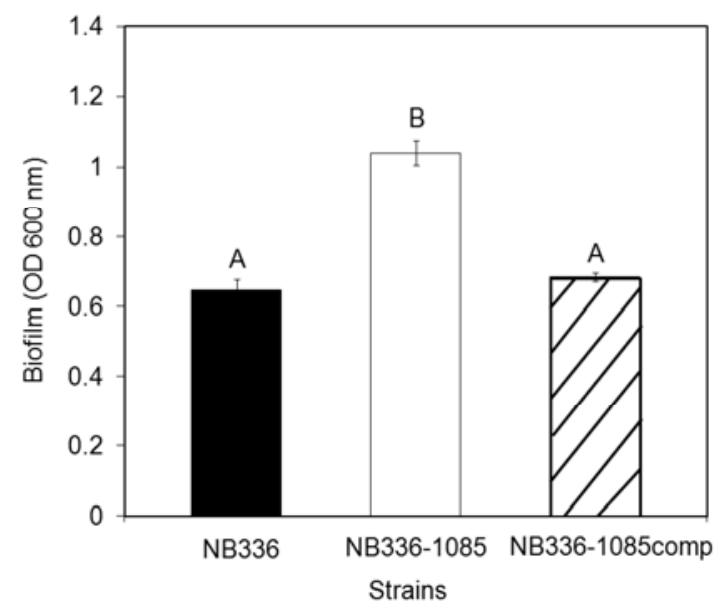

Fig. 5. Biofilm formation by Ralstonia solanacearum strains. Biofilm formation was quantified by measuring the optical density at $600 \mathrm{~nm}\left(\mathrm{OD}_{600}\right)$ of crystal-violet-stained PVC microtiter wells at $48 \mathrm{~h}$ postincubation. Results are the mean of three independent experiments with five replicates each and the error bars represent the standard error of the mean. Different letters indicate significant differences $(P=0.05)$ among the strains according to Tukey's honestly significant difference test. tion methods to test the importance of Flp pili during different stages of pathogenesis. In a biologically representative soil soak inoculation assay, the wild-type NB336 strain but not the mutant NB336-1085 strain caused wilting of potato plants. These results suggest that the mutant strain did not ingress into potato roots or, alternatively, that the bacteria may have entered plant roots but that they differed from the wild-type strain in their ability to colonize potato stems. The nonwilting phenotype of strain NB336-1085 was observed in both the soil-soak and cut-petiole inoculation assays, thus indicating a role for Flp pili for successful infection of the host plant beyond the stages of root adhesion and root colonization by the strain.

What might the role of Flp pili be during disease development? The mutant NB336-1085 strain could multiply in planta but was unable to cause wilting of the potato plants used in the virulence assays, although localized leaf yellowing and necrosis were observed for cut-petiole-inoculated plants. Thus, Flp pili might take part mainly in the late stages of the disease development process, possibly by modulating disease severity rather than the infective ability of the bacterium. A study recently reported that posttranslational modification of Neisseria meningitidis T4P results in the detachment of bacterial cells from cell aggregates which, in turn, allows their spread to new colonization sites. In contrast, a mutant strain that was blocked in pilin modification remained attached to the epithelial cells (Chamot-Rooke et al. 2011). In this regard, it is interesting to note that the Flp pilin of both A. actinomycetemcomitans and $P$. aeruginosa is glycosylated, and the RcpC protein has been implicated as being required for the synthesis of the modified Flp pili (Bernard et al. 2009; Tomich et al. 2006). The mutant NB336-1085 formed significantly greater biofilms than the wild-type and complemented mutant strains. Thus, it is tempting to speculate that, whereas loss of the Flp pilin may cause increased aggregation, modification of the Flp pilin in the wild-type may cause reduced aggregation, resulting in the dissemination of individual cells and subsequent colonization of new sites within the infected host plant. This may also have the additional advantage of avoiding nutrient limitation or exhaustion. Whether the above scenario may relate to the situation in planta requires further investigation, and microscopy studies are needed to observe biofilm formation in the xylem vessels of host plants infected by the wild-type NB336 and mutant NB336-1085 strains.

The tad gene cluster may, however, also play a more direct role in virulence. Most of the proteins encoded by the tad locus are evolutionarily related to type II and type IV secretion systems (Tomich et al. 2007). In the case of $R$. solanacearum, it is estimated that the bacterium exports large repertoires of pathogenicity effectors through the type II in addition to the type III secretion system (Poueymiro and Genin 2009). Indeed, mutants unable to secrete type II secretion-dependent exoproteins lost the ability to cause disease symptoms and to efficiently colonize the plants (Kang et al. 1994). At this stage, we cannot rule out the possibility that the $R$. solanacearum Tad apparatus also transports virulence factors, as had been suggested previously for the Tad system of the human pathogen $A$. actinomycetemcomitans (Wang and Chen 2005).

Although biofilms are suspected of playing a role in $R$. solanacearum-host interaction (Morris and Monier 2003), few studies have been undertaken and the factors that affect $R$. solanacearum biofilm formation are still unknown. $R$. solanacearum has been reported to form biofilm-like aggregations on a PVC surface (Kang et al. 2002; Yao and Allen 2007) and on the surface of tomato seedling roots (Kang et al. 2002; Yao and Allen 2006). It has been proposed that, once inside the plant, biofilms could help either to protect the pathogen from host 
defenses and, thus, contribute to bacterial survival during latent infections and saprophytic life (Stemmer and Sequeira 1987), or it may enable the pathogen to remain anchored to xylem cell walls and filter nutrients from the dilute flow of xylem liquid (Yao and Allen 2007). In this study, both the mutant and the wild-type $R$. solanacearum strains formed biofilms on PVC plastic surfaces at the liquid-air interface. Interestingly, the NB336-1085 mutant strain overproduced biofilms compared with the wild-type NB336 strain. The result was somewhat unexpected, because tad mutants of A. actinomycetemcomitans and $P$. aeruginosa are impaired in biofilm formation on abiotic surfaces (de Bentzmann et al. 2006; Kachlany et al. 2000; Perez et al. 2006; Tomich et al. 2006). Thus, in the case of $R$. solanacearum, the presence of a functional tadA2 gene appears to mask the contribution of other cell surface appendages, such as the T4a pili, to the biofilm formation process. In other words, Flp pili may disturb T4a pili contact with surfaces and, therefore in Flp-deficient mutants, T4a pili can promote a stronger attachment to the surface that results in enhanced biofilm formation relative to the wild-type. This suggests that T4a pili but not Flp pili encoded by the tad gene cluster are important for biofilm formation by $R$. solanacearum. This statement is supported by the fact that T4a pili mutants of $R$. solanacearum AWI (Kang et al. 2002) and Acidovorax avenae subsp. citrulli (Bahar et al. 2009) are severely impaired in biofilm formation on abiotic surfaces.

In conclusion, the results of this study provide strong support that the tad locus in the megaplasmid of $R$. solanacearum is essential for expression of virulence on potato plants. This represents the first report regarding the characterization of a tad gene cluster of a phytopathogenic bacterium, and is the first example to indicate that its presence contributes significantly to plant pathogenesis. In addition to $R$. solanacearum, BLAST searches also identified complete tad loci in various other gram-negative phytopathogenic bacteria, including $\mathrm{Pseu}$ domonas syringae, Agrobacterium tumefaciens, A. vitis, Candidatus Liberibacter, and Pectobacterium carotovorum subsp. atrosepticum, brasiliensis, carotovorum, and wasabiae; as well as in gram-positive phytopathogenic bacteria such as Clavibacter michiganensis, Leifsonia xyli, and Streptomyces scabiei (data not shown). The challenge now is to determine precisely what the specific roles of the $R$. solanacearum tad gene products are in the pathogenesis of bacterial wilt. This knowledge will not only enable a better understanding of this important virulence factor but may also provide significant clues about the functions of the Tad proteins in other phytopathogenic bacteria.

\section{MATERIALS AND METHODS}

\section{Bacterial strains and growth conditions.}

The bacterial strains and plasmids used in this study are listed in Table 2. All $R$. solanacearum strains in this study were derived from wild-type strain NB336 (phylotype II, race 3, biovar 2), obtained from Coen Bezuidenhout Seed Testing Centre (Pretoria, South Africa). $R$. solanacearum strains were grown in CPG broth (Hendrick and Sequeira 1984) or on TZC agar (Kelman 1954) at $30^{\circ} \mathrm{C}$. Escherichia coli strains were grown in Luria-Bertani broth (Miller 1992) at $37^{\circ} \mathrm{C}$. When appropriate, the $E$. coli growth medium was supplemented with ampicillin $(50 \mu \mathrm{g} / \mathrm{ml})$, tetracycline $(10 \mu \mathrm{g} / \mathrm{ml})$, or gentamycin ( $7 \mu \mathrm{g} / \mathrm{ml}$ ). The $R$. solanacearum growth media were supplemented with tetracycline $(10 \mu \mathrm{g} / \mathrm{ml})$ or gentamycin $(15 \mu \mathrm{g} / \mathrm{ml})$. The growth of $R$. solanacearum wild-type and mutant strains was compared in CPG broth. The ability of the bacterial strains to elicit an HR was determined by infiltration of tobacco leaves according to the procedures described by Liu and associates (2001). To prepare inoculum, $R$. solanacearum cultures grown overnight in CPG broth were diluted 50-fold in fresh CPG broth and the cultures were incubated until they reached an optical density at $600 \mathrm{~nm}\left(\mathrm{OD}_{600}\right)$ of 0.8 . The cells were harvested by centrifugation $\left(4000 \times g, 25 \mathrm{~min}, 4^{\circ} \mathrm{C}\right)$ and suspended in sterile distilled water $\left(\mathrm{dH}_{2} \mathrm{O}\right)$ until an $\mathrm{OD}_{600}$ of 0.1 (approximately $1 \times 10^{8} \mathrm{CFU} / \mathrm{ml}$ as determined by dilution plating).

\section{Growth in planta.}

The growth of $R$. solanacearum wild-type and mutant strains was compared in 30-day-old potato plants. The potato plants used in these and in virulence assays were grown from seed of Solanum tuberosum BP1, a commercial cultivar obtained from RSA Seeds (Pretoria, South Africa). Stem inoculations were performed as described previously (Araud-Razou et al. 1998; Frey et al. 1994) by injecting $5 \mu$ l of the standardized bacterial suspension $\left(10^{8} \mathrm{CFU} / \mathrm{ml}\right)$ into each plant, and the inoculated plants were incubated in a greenhouse at 28 to

Table 2. Bacterial strains and plasmids used in this study

\begin{tabular}{|c|c|c|}
\hline Strain or plasmid & Characteristics $^{\mathrm{a}}$ & Reference or source \\
\hline \multicolumn{3}{|l|}{ Strains } \\
\hline \multicolumn{3}{|l|}{ Escherichia coli } \\
\hline DH5 $\alpha$ & $\begin{array}{l}\left.\mathrm{F}^{-} \text {recA1 endA1 hsdR17 deoR thi-1 supE44 gyrA96 relA1 } \Delta \text { (lacZYA-argF }\right) \mathrm{U} 169 \lambda^{-} \\
{[\Phi 80 \mathrm{~d} l a c Z \Delta \mathrm{M} 15]}\end{array}$ & Invitrogen \\
\hline \multicolumn{3}{|c|}{ [\% } \\
\hline NB336 & Wild-type, virulent potato isolate (race 3, biovar 2, phylotype II); $\mathrm{Swm}^{+}, \mathrm{Twt}^{+}, \mathrm{HR}^{+}, \mathrm{EPS}^{+}$ & CBSTC, Pretoria ${ }^{\mathrm{b}}$ \\
\hline NB336-1085 & NB336 insertional mutant defective in $\operatorname{tadA2} ; \mathrm{Gm}^{\mathrm{r}}, \mathrm{Swm}^{+}, \mathrm{Twt}^{+}, \mathrm{HR}^{+}, \mathrm{EPS}^{+}$ & This study \\
\hline NB336-1085comp & NB336-1085 complemented with pLAFR-Lp-1085; $\mathrm{Gm}^{\mathrm{r}}, \mathrm{Tc}^{\mathrm{r}}$ & This study \\
\hline \multicolumn{3}{|c|}{ 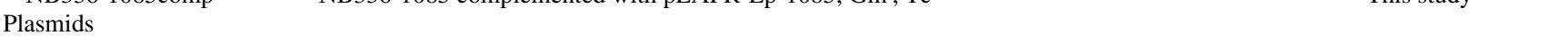 } \\
\hline pUC19 & Cloning vector; ColE1, Amp ${ }^{\mathrm{r}}$, LacZ $\alpha$ peptide & Stratagene \\
\hline pUC19-1085 & $\begin{array}{l}\text { pUC19 containing } 2.306-\mathrm{kb} \text { amplicon harboring full-length } t a d A 2 \text { and flanking up- and } \\
\text { downstream regions, cloned into the EcoRI and HindIII sites of pUC19 }\end{array}$ & This study \\
\hline pGEM-Gent & pGEM-T Easy vector containing gentamycin resistance $\left(\mathrm{Gm}^{\mathrm{r}}\right)$ cassette & Smith 2003 \\
\hline pUC19-1085:: $\mathrm{Gm}^{\mathrm{r}}$ & pUC19-1085 with a Gm ${ }^{\mathrm{r}}$ cassette inserted at the NotI and PstI sites of tadA2 & This study \\
\hline pBluescript SKII (+) & Cloning vector; ColE1, Amp $p^{r}$ LacZ $\alpha$ peptide & Stratagene \\
\hline pLAFR6 & Inc $\mathrm{P}, \mathrm{RK} 2$-derived cosmid vector; $\mathrm{Tc}^{\mathrm{r}}$ & Huynh et al. 1989 \\
\hline pLAFR-Lp & $\begin{array}{l}\text { lac promoter (235 bp) amplicon from pBluescript SKII (+) cloned into the HindIII and XbaI sites } \\
\text { of pLAFR6 }\end{array}$ & This study \\
\hline pLAFR-Lp-1085 & $\begin{array}{l}\text { pLAFR-Lp with the } 1.35-\mathrm{kb} \text { tadA2 gene fragment cloned into the } X b a \mathrm{I} \text { and EcoRI sites } \\
\text { downstream of the lac promoter }\end{array}$ & This study \\
\hline
\end{tabular}

\footnotetext{
${ }^{a}$ Swm, swimming motility; Twt, twitching motility; HR, hypersensitive response on tobacco; EPS, exopolysaccharide; $\mathrm{Gm}^{\mathrm{r}}, \mathrm{Tc}^{\mathrm{r}}$, and $\mathrm{Amp}^{\mathrm{r}}$, resistance to gentamycin, tetracycline, and ampicillin, respectively.

${ }^{\mathrm{b}}$ Coen Bezuidenhout Seed Testing Centre, Pretoria, South Africa.
} 
$30^{\circ} \mathrm{C}$. At each time interval postinoculation, the petiole stub was excised and discarded, and 1.5-cm segments of the stem, obtained from above and below the point of inoculation, were excised and surface sterilized by rinsing the stems in sterile $\mathrm{dH}_{2} \mathrm{O}$ and then in $70 \%$ ethanol. After rinsing again with sterile $\mathrm{dH}_{2} \mathrm{O}$, the stems were homogenized with a Homex 6 homogenizer (Bioreba, Reinach, Switzerland) in $5 \mathrm{ml}$ of sterile $\mathrm{dH}_{2} \mathrm{O}$. Serial dilutions of the stem homogenates were prepared in sterile $\mathrm{dH}_{2} \mathrm{O}$ and plated in triplicate onto TZC to enumerate the viable bacteria.

\section{Bioinformatic analyses.}

The genome sequence of $R$. solanacearum GMI1000 and its annotation is available online. $R$. solanacearum homologues of the Aggregatibacter actinomycetemcomitans flp-rcp-tad genes were identified using the BLAST algorithm and the deduced amino acid sequences were subjected to analysis using different software programs, such as BLAST-P, PSORT, SMART tool, SIGNALP, LipoP, TMPRED, ScanProsite, and ClustalW. These programs are available online.

\section{Recombinant DNA techniques.}

Molecular cloning techniques used in the construction of recombinant plasmids were carried out using standard procedures (Sambrook and Russell 2001). T4 DNA ligase (Roche Diagnostics, Mannheim, Germany) and restriction enzymes (Fermentas, St. Leon-Rot, Germany) were used according to the manufacturers' protocols. Plasmid DNA was extracted from E. coli with a Zyppy Plasmid Miniprep kit, genomic DNA was isolated from $R$. solanacearum strains with a ZR fungal/bacterial DNA isolation kit, and restriction DNA fragments were purified from agarose gels by use of a Zymoclean Gel DNA Recovery kit (all kits obtained from Zymo Research Corp., Orange, CA, U.S.A.). Plasmid constructions were first established in E. coli DH5 $\alpha$ and then transferred to $R$. solanacearum strains. Competent cells were prepared and transformed according to published procedures for $E$. coli (Cohen et al. 1972) and $R$. solanacearum (Allen et al. 1991). PCR assays were performed with Biotaq DNA polymerase (Bioline Inc., Randolph, MA, U.S.A.) and PCR amplicons were purified with the QIAquick PCR purification kit (Qiagen, Hilden, Germany). Primers used in this study were designed from the $R$. solanacearum GMI1000 genome sequence and obtained from Integrated DNA Technologies (Coralville, IA, U.S.A.). Southern blot hybridization was performed using the DIG-High Prime DNA labeling and detection starter kit (Roche Diagnostics). Nucleotide sequencing was performed with the ABIPRISM BigDye terminator v.3.1 cycle sequencing ready reaction kit (Applied Biosystems, Foster City, CA, U.S.A.), followed by resolution on an ABI PRISM 310 genetic analyzer (Applied Biosystems), in accordance with the manufacturer's instructions. All plasmid constructs were verified by restriction endonuclease digestion and by nucleotide sequencing.

\section{Construction of $\operatorname{tadA} 2$ mutant NB336-1085.}

A $2.306-\mathrm{kb}$ DNA fragment containing the putative tadA2 ORF flanked by upstream (534 bp) and downstream (422 bp) sequences was PCR amplified from NB336 genomic DNA using primers TadAZ-F (5'-CGTCGAGAATTCCGGGCAGTT GC-3') and TadAB-R (5'-CAACCGCCTGCGAAGCTTCTTC G-3'). The resulting amplicon was digested with both EcoRI and HindIII (underlined above) and cloned into the identical sites of pUC19 to generate pUC-1085. The recombinant plasmid was digested with NotI and PstI, which released a 761-bp fragment from within $\operatorname{tad} A 2$, and the gentamycin resistanceencoding cassette aacCI, excised from pGEM-Gent (Smith 2003) by digestion with NotI and PstI, was cloned into the deletion site, creating pUC-1085::Gm ${ }^{\mathrm{r}}$. The mutant allele was introduced into $R$. solanacearum NB336 and the resulting strains were selected by gentamycin resistance on TZC agar. Allelic replacement of the tadA2 gene in the $R$. solanacearum megaplasmid was confirmed by PCR and Southern blot hybridization (data not shown). The confirmed tadA2 mutant was designated NB336-1085.

\section{Complementation of NB336-1085.}

The 235-bp lac promoter of the plasmid pBluescript SKII (+) was PCR amplified with primers LacP-F (5'-CGGTATCTAGA TTTTGTTCCCTTTAGTGAG-3') and LacP-R (5'-TAATGCA GCTGGCACGAAAGCTTTCCC-3'). The amplicon was digested with both XbaI and HindIII (underlined above) and cloned into the identical sites of the broad-host-range cosmid pLAFR6 (Huynh et al. 1989) to generate pLAFR-Lp. A 1.35$\mathrm{kb}$ fragment containing a full-length copy of tadA2 was PCR amplified from NB336 genomic DNA using primers CpaF2-F (5'-CGACCAGAGCGCGAATTCAGACATGGAATC- ${ }^{\prime}$ ) and CpaF2-R (5'-GGAACGGAACTCTAGATGACACAACCCAT CG-3'), digested with both $E c o$ RI and $X b a$ I (underlined above), and cloned into LAFR-Lp. The complementation plasmid pLAFR-Lp-1085 was introduced into NB336-1085 and complemented strains were selected by tetracycline resistance on TZC agar. The complemented mutant strain was designated NB336-1085comp.

\section{Electron microscopy.}

Cultures of the $R$. solanacearum strains were prepared for TEM according to the methods of Stemmer and Sequeira (1987). The cultures were grown statically at $30^{\circ} \mathrm{C}$ in sterile glass petri dishes containing $2 \mathrm{ml}$ of broth $(0.1 \%$ [wt/vol] casein hydrolysate, $1 \%$ [wt/vol] peptone, and $20 \mathrm{mM}$ glutamate; $\mathrm{pH} 7.3$ to 7.5 ). The cultures were transferred twice to fresh broth, using only the pellicle as the inoculum. After $48 \mathrm{~h}$ of growth, a 200-mesh Formvar-coated copper grid was floated on the surface of the culture for $5 \mathrm{~min}$ and then rinsed with sterile $\mathrm{dH}_{2} \mathrm{O}$ to remove debris. The copper grids were negatively stained in $1 \%$ uranyl acetate for $30 \mathrm{~s}$, the excess stain was wicked away, and the grids were viewed in a JEOL 2100F transmission electron microscope at $80 \mathrm{kV}$.

\section{EPS production.}

EPS was extracted from $R$. solanacearum culture supernatants, as described by Brumbley and Denny (1990), and the concentration of galactosamine was determined using a modified Elson-Morgan reaction and $\mathrm{N}$-acetylgalactosamine as standard (Jang et al. 2005).

\section{Motility assays.}

Motility assays were performed using standardized cultures $\left(\mathrm{OD}_{600}=0.1\right)$ of the $R$. solanacearum strains, as described by Liu and associates (2001). Swimming motility was assayed by stab inoculation of motility agar (1\% [wt/vol] tryptone and $0.3 \%$ [wt/vol] agar), followed by incubation of the agar plates for $48 \mathrm{~h}$ at $30^{\circ} \mathrm{C}$. Twitching motility was assayed on CPG agar. After incubation overnight at $30^{\circ} \mathrm{C}$, colonies were examined for twitching motility by placing a petri dish, without its lid, on the stage of a Nikon light microscope equipped with a $10 \times$ objective (Nikon Optiphot, Tokyo). The images were acquired with a Nikon DXM 1200 digital camera.

\section{Virulence assays.}

Virulence tests of $R$. solanacearum strains were conducted on susceptible potato plants, as described by Liu and associates (2001), except that the plants were not watered for $24 \mathrm{~h}$ prior to inoculation (Williamson et al. 2002). Potato plants (30 
days old, $15 \mathrm{~cm}$ in height) were inoculated by drenching the soil $(0.5 \mathrm{~kg})$ in $20-\mathrm{cm}$ pots with $50 \mathrm{ml}$ of the bacterial suspension $\left(10^{8} \mathrm{CFU} / \mathrm{ml}\right)$ or by applying $5 \mu \mathrm{l}$ of the inoculum to the stub of freshly severed leaf petioles. As controls, potato plants were likewise inoculated with sterile $\mathrm{dH}_{2} \mathrm{O}$. The plants were maintained under greenhouse conditions that favor bacterial wilt development (i.e., temperature of 28 to $30^{\circ} \mathrm{C}$, relative humidity of 85 to $95 \%$, and natural day and night cycles) (Prior et al. 1996). The plants were rated daily for 30 days using a 0 to 4 disease index, with 0 being healthy (Fock et al. 2000, 2001).

\section{Biofilm formation.}

Biofilm formation on an abiotic surface was determined using a quantitative plate assay (Yao and Allen 2007) with minor modification. Briefly, a 96-well PVC plate (Nunc, Roskilda, Denmark), containing $50 \mu \mathrm{l}$ of CPG broth per well, was inoculated with $150 \mu \mathrm{l}$ of standardized cultures $\left(\mathrm{OD}_{600}=0.1\right)$ of the $R$. solanacearum strains. The plates were sealed with plastic wrap and incubated without shaking for $48 \mathrm{~h}$ at $30^{\circ} \mathrm{C}$. Crystal violet staining and biofilm quantification were performed, as described previously (O'Toole and Kolter 1998), except that the optical density was determined at $\mathrm{OD}_{600}$.

\section{Statistical analyses.}

Quantitative assays were analyzed by using analysis of variance at the 95\% level and Tukey's HSD test for mean comparison. All statistical analyses were performed using JMP software (v.5; SAS Institute Inc., Cary, NC, U.S.A.).

\section{ACKNOWLEDGMENTS}

This work was funded by the National Research Foundation of South Africa. We thank A. Hall and C. van der Merwe for assistance with electron microscopy.

\section{LITERATURE CITED}

Aldon, D., Brito, B., Boucher, C., and Genin, S. 2000. A bacterial sensor of plant-cell contact controls the transcriptional induction of Ralstonia solanacearum pathogenicity genes. EMBO (Eur. Mol. Biol. Organ.) J. 19:2304-2314.

Allen, C. A., Huang, Y., and Sequeira, L. 1991. Cloning of genes affecting polygalacturonase production in Pseudomonas solanacearum. Mol. Plant-Microbe Interact. 4:147-154.

Araud-Razou, I., Vasse, J., Montrozier, H., Etchebar, C., and Trigalet, A. 1998. Detection and visualization of the major acidic exopolysaccharide of Ralstonia solanacearum and its role in tomato root infection and vascular colonization. Eur. J. Plant Pathol. 104:795-809.

Bahar, O., Goffer, T., and Burdman, S. 2009. Type IV pili are required for virulence, twitching motility, and biofilm formation of Acidovorax avenae subsp. citrulli. Mol. Plant-Microbe Interact. 22:909-920.

Bernard, C. S., Bordi, C., Termine, E., Filloux, A., and de Bentzmann, S. 2009. Organization and PprB-dependent control of the Pseudomonas aeruginosa tad locus, involved in Flp pilus biology. J. Bacteriol. 191:1961-1973.

Bhattacharjee, M. K., Kachlany, S. C., Fine, D. H., and Figurski, D. H. 2001. Nonspecific adherence and fibril biogenesis by Actinobacillus actinomycetemcomitans: TadA protein is an ATPase. J. Bacteriol. 183:5927-5936.

Brito, B., Marenda, M., Barberis, P., Boucher, C., and Genin, S. 1999. prhJ and $h r p G$, two new components of the plant signal dependent regulatory cascade controlled by PrhA in Ralstonia solanacearum. Mol. Microbiol. 31:237-251.

Brumbley, S. M., and Denny, T. P. 1990. Cloning of phcA from wild-type Pseudomonas solanacearum, a gene that when mutated alters expression of multiple traits that contribute to virulence. J. Bacteriol. 172:5677-5685

Buttner, D., and Bonas, U. 2002. Getting across-bacterial type III effector proteins on their way to the plant cell. EMBO (Eur. Mol. Biol. Organ.) J. 21:5313-5322.

Chamot-Rooke, J., Mikaty, G., Malosse, C., Soyer, M., Dumont, A., Gault, J., Imhaus, A. F., Martin, P., Trellet, M., Clary, G., Chafey, P., Camoin,
L., Nilges, M., Nassif, X., and Duménil, G. 2011. Posttranslational modification of pili upon cell contact triggers $N$. meningitidis dissemination. Science 331:778-782.

Clock, S. A., Planet, P. J., Perez, B. A., and Figurski, D. H. 2008. Outer membrane components of the Tad (tight adherence) secretion of Aggregatibacter actinomycetemcomitans J. Bacteriol. 190:980-990.

Cohen, S. N., Chang, A. C. Y., and Hsu, L. 1972. Nonchromosomal antibiotic resistance in bacteria: Genetic transformation of Escherichia coli by R-factor DNA. Proc. Natl. Acad. Sci. U.S.A. 69:2110-2114.

Craig, L., and Li, J. 2008. Type IV pili: Paradoxes in form and function. Curr. Opin. Struct. Biol. 18:267-277.

Cunnac, S., Occhialini, A., Barberis, P., Boucher, C., and Genin, S. 2004. Inventory and functional analysis of the large Hrp regulon in Ralstonia solanacearum: Identification of novel effector proteins translocated to plant host cells through the type III secretion system. Mol. Microbiol. 53:115-128.

Danhorn, T., and Fuqua, C. 2007. Biofilm formation by plant-associated bacteria. Annu. Rev. Microbiol. 61:401-422.

de Bentzmann, S., Aurouze, M., Ball, G., and Filloux, A. 2006. FppA, a novel Pseudomonas aeruginosa prepilin peptidase involved in assembly of type IVb pili. J. Bacteriol. 188:4851-4860.

Denny, T. P., and Baek, S. R. 1991. Genetic evidence that extracellular polysaccharide is a virulence factor of Pseudomonas solanacearum. Mol. Plant-Microbe Interact. 4:198-206.

Denny, T. P., Makini, F. W., and Brumbley, S. M. 1988. Characterization of Pseudomonas solanacearum Tn5 mutants deficient in extracellular polysaccharide. Mol. Plant-Microbe Interact. 1:215-223.

Fernandez, L., Marquez, I., and Guijarro, J. A. 2004. Identification of specific in vivo-induced genes in Yersinia ruckeri and analysis of ruckerbactin, a catecholate siderophore iron acquisition system. Appl. Environ. Microbiol. 70:5199-5207.

Fock, I., Collonnier, C., Purwito, A., Luisetti, J., Souvannavong, V., Vedel, F., Servaes, A., Ambroise, A., Kodja, H., Ducreux, G., and Sihachakr, D. 2000. Resistance to bacterial wilt in somatic hybrids between Solanum tuberosum and Solanum phureja. Plant Sci. 160:165-176.

Fock, I., Collonnier, C., Luisetti, J., Purwito, A., Souvannavong, V., Vedel, F., Servaes, A., Ambroise, A., Kodja, H., Ducreux, G., and Sihachakr, D. 2001. Use of Solanum stenotomum for introduction of resistance to bacterial wilt in somatic hybrids of potato. Plant Physiol. Biochem. 39:899-908.

Frey, P., Prior, P., Marie, C., Koutoujansky, A., Trigalet-Demery, D., and Trigalet, A. 1994. Hrp-mutants of Pseudomonas solanacearum as potential biocontrol agents of tomato bacterial wilt. Appl. Environ. Microbiol. 60:3175-3181.

Fronzes, R., Remaut, H., and Waksman, G. 2008. Architectures and biogenesis of non-flagellar protein appendages in Gram-negative bacteria. EMBO (Eur. Mol. Biol. Organ.) J. 27:2271-2280.

Fuller, T. E., Kennedy, M. J., and Lowery, D. E. 2000. Identification of Pasteurella multocida virulence genes in a septicemic mouse model using signature tagged mutagenesis. Microb. Pathog. 29:25-38.

Genin, S., and Boucher, C. A. 2004. Lessons learned from the genome analysis of Ralstonia solanacearum. Annu. Rev. Phytopathol. 42:107134.

Gerlach, R. G., and Hensel, M. 2007. Protein secretion systems and adhesins: The molecular armory of gram-negative pathogens. Int. J. Med. Microbiol. 297:401-415.

Gonzalez, E. T., and Allen, C. 2003. Characterization of a Ralstonia solanacearum operon required for polygalacturonate degradation and uptake of galacturonic acid. Mol. Plant-Microbe Interact. 16:536-544.

Hayward, A. C. 1991. Biology and epidemiology of bacterial wilt caused by Pseudomonas solanacearum. Annu. Rev. Phytopathol. 29:65-87.

Henderson, B., Wilson, M., McNab, R., and Lax, A. J. 1999. Cellular Microbiology. Bacteria-Host Interactions in Health and Disease. John Wiley and Sons, New York.

Hendrick, C., and Sequeira, L. 1984. Lipopolysaccharide-defective mutants of the wilt pathogen Pseudomonas solanacearum. Appl. Environ. Microbiol. 48:94-101.

Hikichi, Y., Yoshimochi, T., Tsujimoto, S., Shinohara, R., Nakaho, K., Kanda, A., Kiba, A., and Ohnishi, K. 2007. Global regulation of pathogenicity mechanism of Ralstonia solanacearum. Plant Biotechnol. 24:149-154.

Huynh, T. V., Dahlbeck, D., and Staskawicz, B. J. 1989. Bacterial blight of soybean: Regulation of a pathogen gene determining host cultivar specificity. Science 245:1374-1377.

Jang, J. H., Hia, H. C., Ike, M., Inoue, C., Fujita, M., and Yoshida, T. 2005. Acid hydrolysis and quantitative determination of total hexosamines of an exopolysaccharide produced by Citrobacter spp. Biotechnol. Lett. 27:13-18.

Janse, J. D., van den Beld, H. E., Elphinstone, J., Simpkins, S., Tjou-TamSin, N. A. A., and van Vaerenbergh, J. 2004. Introduction to Europe of 
Ralstonia solanacearum biovar 2, race 3 in pelargonium zonale cuttings. J. Plant Pathol. 86:147-155.

Kachlany, S. C., Planet, P. J., Bhattacharjee, M. K., Kollia, E., DeSalle, R., Fine, D. H., and Figurski, D. H. 2000. Nonspecific adherence of Actinobacillus actinomycetemcomitans requires genes widespread in bacteria and archaea. J. Bacteriol. 182:6169-6176.

Kachlany, S. C., Planet, P. J., DeSalle, R., Fine, D. H., Figurski, D. H., and Kaplan, J. 2001. flp-1, the first representative of a new pilin gene subfamily, is required for non-specific adherence of Actinobacillus actinomycetemcomitans. Mol. Microbiol. 40:542-554.

Kang, Y., Huang, J. Z., Mao, G. Z., He, L. Y., and Schell, M. A. 1994. Dramatically reduced virulence of mutants of Pseudomonas solanacearum defective in export of extracellular proteins across the outer membrane. Mol. Plant-Microbe Interact. 7:370-377.

Kang, Y., Liu, H., Genin, S., Schell, M. A., and Denny, P. T. 2002. Ralstonia solanacearum requires type IV pili to adhere to multiple surfaces and for natural transformation and virulence. Mol. Microbiol. 2:427437.

Kelman, A. 1954. The relationship of pathogenicity in Pseudomonas solanacearum to colony appearance in a tetrazolium medium. Phytopathology 44:693-695.

Kram, K. E., Hovel-Miner, G. A., Tomich, M., and Figurski, D. H. 2008. Transcriptional regulation of the tad locus in Aggregatibacter actinomycetemcomitans: A termination cascade. J. Bacteriol. 190:3859-3868.

Liu, H., Kang, Y., Genin, S., Schell, M. A., and Denny, T. P. 2001. Twitching motility of Ralstonia solanacearum requires a type IV pilus system. Microbiology 147:3215-3229.

Liu, H., Zhang, S., Schell, M. A., and Denny, T. P. 2005. Pyramiding unmarked deletions in Ralstonia solanacearum shows that secreted proteins in addition to plant cell-wall-degrading enzymes contribute to virulence. Mol. Plant-Microbe Interact. 18:1296-1305.

Mattick, J. S., Whitchurch, C. B., and Alm, R. A. 1996. The molecular genetics of type IV fimbriae in Pseudomonas aeruginosa. Gene 179:147155 .

McGarvey, J. A., Denny, T. P., and Schell, M. A. 1999. Spatial-temporal and quantitative analysis of growth and EPS production by Ralstonia solanacearum in resistant and susceptible tomato cultivars. Phytopathology 89:1233-1239.

Miller, J. H. 1992. A Short Course in Bacterial Genetics: A Laboratory Manual and Handbook for Escherichia coli and Related Bacteria. Cold Spring Harbor Laboratory Press, Cold Spring Harbor, NY, U.S.A.

Morris, C. E., and Monier, J. M. 2003. The ecological significance of biofilm formation by plant-associated bacteria. Annu. Rev. Phytopathol. 41:429-453.

Nika, J. R., Latimer, J. L., Ward, C. K., Blick, R. J., Wagner, N. J., Cope, L. D., Mahairas, G. G., Munson, R. S., and Hansen, E. J. 2002. Haemophilus ducreyi requires the flp gene cluster for microcolony formation in vitro. Infect. Immun. 70:2965-2975.

O'Toole, G. A., and Kolter, R. 1998. Flagellar and twitching motility are necessary for Pseudomonas aeruginosa biofilm development. Mol. Microbiol. 30:295-304.

Pelicic, V. 2008. Type IV pili: E pluribus unum? Mol. Microbiol. 68:827837.

Perez, B. A., Planet, P. J., Kachlany, S. C., Tomich, M., Fine, D. H., and Figurski, D. H. 2006. Genetic analysis of the requirement for $f l p-2$, tadV, and rcpB in Actinobacillus actinomycetemcomitans biofilm formation. J. Bacteriol. 188:6361-6375.

Planet, P. J., Kachlany, S. C., DeSalle, R., and Figurski, D. H. 2001. Phylogeny of genes for secretion NTPases: Identification of the widespread tadA subfamily and development of a diagnostic key for gene classification. Proc. Natl. Acad. Sci. U.S.A. 98:2503-2508.

Planet, P. J., Kachlany, S. C., Fine, D. H., DeSalle, R., and Figurski, D. H. 2003. The widespread colonization island of Actinobacillus actinomycetemcomitans. Nat. Genet. 34:193-198.

Possot, O., and Pugsley, A. P. 1994. Molecular characterization of PulE, a protein required for pullulanase secretion. Mol. Microbiol. 12:287-299.

Poueymiro, M., and Genin, S. 2009. Secreted proteins from Ralstonia solanacearum: A hundred tricks to kill a plant. Curr. Opin. Microbiol. 12:44-52.

Prior, P., Bart, S., Leclercq, S., Darrasse, A., and Anais, G. 1996. Resistance to bacterial wilt in tomato as discerned by spread of Pseudomonas (Burkholderia) solanacearum in the stem tissues. Plant Pathol. 45:720-726.

Salanoubat, M., Genin, S., Artiguenave, F., Gouzy, J., Mangenot, S., Arlat, M., Billault, A., Brottier, P., Camus, J., Cattolico, L., Chandler, M., Choisne, N., Claudel-Renard, C., Cunnac, S., Demange, N., Gaspin, C.,
Lavie, M., Moisan, A., Robert, C., Saurin, W., Schiex, T., Siguier, P., Thebault, P., Whalen, M., Wincker, P., Levy, M., Weissenbach, J., and Boucher, C. A. 2002. Genome sequence of the plant pathogen Ralstonia solanacearum. Nature 415:497-502.

Sambrook, J., and Russel, D. W. 2001. Molecular Cloning: A Laboratory Manual. Cold Spring Harbor Laboratory Press, Cold Spring Harbor, NY, U.S.A

Schell, M. A. 2000. Control of virulence and pathogenicity genes of Ralstonia solanacearum by an elaborate sensory network. Annu. Rev. Phytopathol. 38:263-292.

Schreiner, H. C., Sinatra, K., Kaplan, J. B., Furgang, D., Kachlany, S. C., Planet, P. J., Perez, B. A., Figurski, D. H., and Fine, D. H. 2003. Tightadherence genes of Actinobacillus actinomycetemcomitans are required for virulence in a rat model. Proc. Natl. Acad. Sci. U.S.A. 100:72957300 .

Smith, J. J. 2003. Towards the development of a biofilm-specific expression system: Effects of different promoters, gene dosage and growth phases on extracellular expression of Pseudomonas aeruginosa DSM1707 alkaline protease. M.Sc. thesis, Department of Microbiology and Plant Pathology, University of Pretoria, South Africa.

Spinola, S. M., Fortney, K. R., Katz, B. P., Latimer, J. L., Mock, J. R., Vakevainen, M., and Hansen, E. J. 2003. Haemophilus ducreyi requires an intact $f l p$ gene cluster for virulence in humans. Infect. Immun. 71:7178-7182.

Stemmer, W. P. C., and Sequeira, L. 1987. Fimbriae of phytopathogenic and symbiotic bacteria. Phytopathology 77:1633-1639.

Swanson, J. K., Yao, J., Tans-Kersten, J. K., and Allen, C. 2005. Behavior of Ralstonia solanacearum race 3 biovar 2 during latent and active infection of geranium. Phytopathology 95:136-143.

Tans-Kersten, J., Huang, H. Y., and Allen, C. 2001. Ralstonia solanacearum needs motility for invasive virulence on tomato. J. Bacteriol. 183:3597-3605.

Tomich, M., Fine, D. H., and Figurski, D. H. 2006. The TadV protein of Actinobacillus actinomycetemcomitans is a novel aspartic acid prepilin peptidase required for maturation of the Flp1 pilin and TadE and TadF pseudopilins. J. Bacteriol. 188:6899-6914.

Tomich, M., Planet, P. J., and Figurski, D. H. 2007. The tad locus: Postcards from the widespread colonization island. Nat. Rev. Microbiol. 5:363-375.

van Gijsegem, F., Vasse, J., Camus, J. C., Marenda, M., and Boucher, C. 2000. Ralstonia solanacearum produces hrp-dependent pili that are required for PopA secretion but not for attachment of bacteria to plant cells. Mol. Microbiol. 36:249-260.

Vasse, J., Frey, P., and Trigalet, A. 1995. Microscopic studies of intercellular infection and protoxylem invasion of tomato roots by Pseudomonas solanacearum. Mol. Plant-Microbe Interact. 8:241-251.

Vasse, J., Danoun, S., and Trigalet, A. 2005. Microscopic studies of root infection in resistant tomato cultivar Hawaii7996. Pages 285-291 in: Bacterial Wilt Disease and the Ralstonia solanacearum Species Complex. C. Allen, P. Prior, and A. C. Hayward, eds. American Phytopathological Society, St. Paul, MN, U.S.A.

Wall, D., and Kaiser, D. 1999. Type IV pili and cell motility. Mol. Microbiol. 32:1-10.

Wang, Y., and Chen, C. 2005. Mutation analysis of the flp operon in Actinobacillus actinomycetemcomitans. Gene 351:61-71.

Whitchurch, C. B., Hobbs, M., Livingston, S. P., Krishnapillai, V., and Mattick, J. S. 1991. Characterization of a Pseudomonas aeruginosa twitching motility gene and evidence for a specialized protein export system widespread in eubacteria. Gene 101:33-44.

Williamson, L., Hudelson, B. D., and Allen, C. 2002. Ralstonia solanacearum strains isolated from geranium belong to Race 3 and are pathogenic on potato. Plant Dis. 86:987-991.

Yao, J., and Allen, C. 2006. Chemotaxis is required for virulence and competitive fitness in the bacterial wilt pathogen Ralstonia solanacearum. J. Bacteriol. 188:3697-3708.

Yao, J., and Allen, C. 2007. The plant pathogen Ralstonia solanacearum needs aerotaxis for normal biofilm formation and interactions with its tomato host. J. Bacteriol. 189:6415-6424.

\section{AUTHOR-RECOMMENDED INTERNET RESOURCES}

INRA's $R$. solanacearum database:

sequence.toulouse.inra.fr/R. solanacearum.html

ExPasy Bioinformatics Resource Portal: au.expasy.org/tools 